\title{
Risk, knowledge and preventive measures of smallholder dairy farmers in northern Malawi with regard to zoonotic brucellosis and bovine tuberculosis
}

\author{
Authors: \\ Stanly Fon Tebug ${ }^{1,6}$ \\ Gilson R. Njunga ${ }^{2}$ \\ Mizeck G.G. Chagunda ${ }^{3}$ \\ Jacob P. Mapemba ${ }^{4}$ \\ Julius Awah-Ndukum ${ }^{5}$ \\ Steffi Wiedemann ${ }^{6}$

\section{Affiliations:} \\ ${ }^{1}$ International Livestock \\ Research Institute, Kenya \\ ${ }^{2}$ Central Veterinary \\ Laboratory, Malawi \\ ${ }^{3}$ Future Farming Systems \\ Group, Scottish Agricultural \\ College, Scotland \\ ${ }^{4}$ World University Service of \\ Canada \\ ${ }^{5}$ School of Biomedical \\ and Biological Sciences, \\ University of Plymouth, \\ Devon \\ ${ }^{6}$ Institute of Animal Breeding \\ and Husbandry, University of \\ Kiel, Germany
}

\section{Correspondence to:}

Steffi Wiedemann

\section{Email:}

swiedemann@tierzucht.

uni-kiel.de

\section{Postal address:}

Institute of Animal Breeding and Husbandry, ChristianAlbrechts-University Kiel, Olshausenstrasse 40, 24098 Kiel, Germany

\section{Dates:}

Received: 20 March 2013 Accepted: 31 Oct. 2013 Published: 28 Feb. 2014
Milk production using local cattle breed-types is an age-old practice in Malawi. Although dairy farming is becoming more common as a result of the increasing population and demand for milk and milk products, there is limited knowledge of the farmers' awareness of zoonotic disease risks, their preventative practices and the disease burden in animals. This study determined dairy farmers' general knowledge of zoonoses, assessed their risks for infection with zoonotic bovine tuberculosis (bTB) and brucellosis, and evaluated farm practices to prevent disease transmission. A questionnaire was drawn up and administered by the authors. It was used to collect information about the knowledge and preventive practices of 140 out of 684 registered dairy farmers at Mzuzu Agricultural Development Division, northern Malawi. During a second visit to 60 out of the 140 farms, a total of 156 and 95 cattle were tested for brucellosis and tuberculosis, respectively. Most farmers (77.1\%) knew or had heard of zoonotic diseases, whilst $75.0 \%$ correctly named at least one zoonotic disease. More survey participants named tuberculosis as a zoonotic disease compared to brucellosis (74.3\% versus $2.9 \%)$. The most commonly named means of transmission were milk $(67.0 \%)$ and meat (56.0\%). Almost all survey participants (96.4\%) practised at least one farm activity that could lead to potential transmission of brucellosis or bTB, including sale $(67.0 \%)$ and consumption (34.0\%) of unpasteurised milk. Antibodies against brucellosis were found in 12 cattle $(7.7 \%)$, whilst one animal $(1.1 \%)$ reacted to the tuberculin skin test. General knowledge about possible transmission of diseases between humans and animals was high, although most farmers practised risk behaviours that could potentially expose the public to milk-borne zoonotic diseases such as brucellosis and bTB. Furthermore, some animals had positive results for brucellosis and tuberculosis tests. Therefore, improvement of zoonotic disease prevention programmes, as well as further investigation into the prevalence and risk factors for zoonoses, is recommended.

\section{Introduction}

Dairy farming is gaining importance in Malawi. This is a result of the increasing population and demand for milk and milk products in the country's major cities. Most dairy farmers are registered and organised into about 50 milk bulking groups (MBGs) around the country's major cities: Blantyre (southern region), Lilongwe (central region) and Mzuzu (northern region) (Banda et al. 2011). The MBGs are mostly run and managed by farmers who collect milk from members within a radius of eight $\mathrm{km}$. Following milk testing on specific gravity and alcohol testing for acidity, milk is bulked in a cooling tank. Milk is bought in bulk by the processors and a bonus is paid to the participating farmers for higher-bulk quantities. The dairy cattle breeds are predominantly Holstein-Friesians, Jerseys and their crosses with the indigenous Malawi Zebu (Banda et al. 2011; Tebug et al. 2012a). These animals are mainly stall-fed or grazed on communal pastureland near human dwellings. Although smallholder dairy farming plays a salient role in meeting the increasing demand for milk as well as milk products, and serves as an important source of employment in Malawi, these animals may also transmit diseases like brucellosis and tuberculosis to humans.

Brucellosis and tuberculosis are considered to be the most important and widespread zoonotic diseases (WHO/FAO/OIE 2004). In sub-Saharan Africa, prevalence rates of brucellosis in humans as high as 13.0\% have been reported in some communities (Kunda et al. 2007; Schelling et al. 2003; Swai \& Schoonman 2009). Malawi is described as non-endemic, because no case of brucellosis has been documented in humans (Pappas et al. 2006). However, pyrexia of unknown origin is

How to cite this article: Tebug, S.F., Njunga, G.R., Chagunda, M.G.G., Mapemba, J.P., Awah-Ndukum, J. \& Wiedemann, S., 2014, 'Risk How to cite this article: Tebug, S.F., Njunga, G.R., Chagunda, M.G.G., Mapemba, J.P., Awah-Ndukum, J. \& Wiedemann, S., 2014, "Risk, tuberculosis', Onderstepoort Journal of Veterinary Research 81(1), Art. \#594, 6 pages. http://dx.doi.org/10.4102/ojvr.v81i1.594 Copyright: @ 2014. The Authors. Licensee: AOSIS OpenJournals. This work is licensed under the Creative Commons Attribution License. 
not uncommon (Walsh et al. 2000). In contrast, tuberculosis in humans is relatively well documented and continues to be a major public health problem in Malawi (Bowie 2006; Nyirenda 2006). According to the WHO Global TB Control Report for 2012 there was an estimated prevalence rate of 164 per 100000 population for tuberculosis (all forms) in the year 2011 (OIE 2012). Though no case of human tuberculosis due to Mycobacterium bovis (M. bovis) (bovine tuberculosis, bTB) has been reported in the country, isolation of $M$. bovis from milk and human tissues samples elsewhere is not uncommon (Kazwala et al. 1998, 2001).

In cattle, recent reports show that the prevalence rates of bTB are as high as $13.2 \%$ in the neighbouring countries of Tanzania and Zambia (Swai et al. 2005; Swai \& Schoonman 2012). Similarly, prevalence rates of brucellosis ranging from $1.2 \%$ to $14.0 \%$ have been reported in cattle reared in different livestock systems in Tanzania and Zambia (Chimana et al. 2010; Karimuribo et al. 2007). The most recent study carried out on Malawian cattle in 1986 revealed a prevalence of $3.8 \%$ and $0.3 \%$ for bTB and brucellosis, respectively (Bedard, Martin \& Chinombo 1993).

Both brucellosis and tuberculosis are considered to be occupational hazards; consumption of unpasteurised milk and physical contact with infected animals have been identified as the two most common routes for animal-tohuman transmission (Fetene, Kebede \& Alem 2011; Makita et al. 2008; Schelling et al. 2003). Livestock farming is believed to be an at-risk occupation, since close contact with animals is inevitable during routine farm activities (Shitaye, Tsegaye \& Pavlik 2007; Swai \& Schoonman 2009, 2010). Furthermore, cultural habits such as the consumption of fresh or soured milk may hamper preventive measures. Low levels of formal education may further render knowledge dissemination and control programmes to be difficult (Ayele et al. 2004; Shitaye et al. 2007). The risk of transmission of bTB and brucellosis has been reported to be influenced by livestock-keeping systems and environmental factors such as closeness to stock routes, access to surface drinking water, location of farms, age of animals and farmers' knowledge of preventive measures (Kazwala et al. 2001; Swai \& Schoonman 2010). Disease control schemes, including compensation to farmers for infected animals that have to be culled, are not really feasible - this is mainly due to limited resources in most developing countries, including Malawi. Despite this, like in most parts of Africa, little official information about occurrence of bTB and brucellosis is available for Malawi (McDermott \& Arimi 2002). Therefore, information about livestock owners' awareness, disease identification skills and preventive farm practices, which have received more recent attention, could be used to optimise disease control (John, Kazwala \& Mfinanga 2008; Mosalagae, Pfukenyi \& Matope 2011; Munyeme et al. 2010).

The present study in the northern region of Malawi was designed to determine dairy cattle farmers' general knowledge about zoonotic diseases and preventive farm practices, as well as risk of transmission from dairy cattle to farmers with regard to bTB and brucellosis.

\section{Materials and methods}

\section{Study area, population and sampling strategy}

The present study was carried out in two districts (Mzimba and Nkhata Bay) of the northern region of Malawi. Over $90.0 \%$ of the dairy cattle population in the region is found in these districts (Banda et al. 2012; Mzuzu Agricultural Development Division 2009). The study population comprised 684 farmers, who were organised into 12 MBGs. Each MBG had an average of 42 (range: 4-65) member farms, and each member farm had an average of 2.2 (range: 1-9) animals, including 1.2 cows per farm (Banda et al. 2012; Tebug et al. 2012a, 2012b). Mzuzu Agricultural Development Division provided a list of MBGs and dairy farmers.

The data used in this study were collected in two phases. The first phase was conducted between February 2011 and June 2011. Seven MBGs were randomly selected using a table of random numbers, from which $30.0 \%(140 / 472)$ of the farmers were selected and included in the survey. The second phase was carried out during the month of April 2011. One hundred and fifty-six animals from 138 farms in all 12 MBGs (146 cows and 10 bulls) and 95 cows from 74 farms were randomly selected and tested for brucellosis and bTB, respectively.

\section{Knowledge and practices of dairy farmers with regard to zoonoses}

A questionnaire was developed to assess farmers' general knowledge about zoonotic diseases, as well as preventive farm practices with regard to bTB and brucellosis. Farmers were interviewed by the same team, which was comprised of the first author (SFT) and a veterinary assistant. This questionnaire was pre-tested for clarity, and to avoid confounding questions, on a pilot group of 15 farmers; in the case of inconsistent questions, it was modified accordingly. Information contained in the first section included: (1) the location of the farm; (2) age and sex of the farm owner; (3) duration that the farmer had been dairy farming; (4) herd size; and (5) origin of the animals. In the second section, knowledge of zoonotic diseases was assessed. Farmers were asked: (1) if they knew or had heard of a disease that is naturally transmitted between animals and man; (2) to name or describe known zoonotic disease(s); and (3) to state known route(s) of transmission. In the last section, preventive measures against zoonoses (such as bTB and brucellosis) and milk-handling practices were assessed. In this section, farmers were asked: (1) if they or any family member had ever undergone medical examination for zoonotic diseases; (2) if their animals had ever been tested by a veterinarian for any zoonotic diseases; (3) whether or not milk was processed or boiled before consumption; and (4) where the milk was sold.

\section{Brucella antibody and tuberculin skin test}

Blood samples (about 7.5 mL) were collected from the jugular vein of the cattle. After coagulation and centrifugation (1500 x $15 \mathrm{~min}$ ) serum was extracted and stored at $2{ }^{\circ} \mathrm{C}-4{ }^{\circ} \mathrm{C}$ for 3-21 days until analysis was carried out. A competitive 
Enzyme Linked Immunosorbent Assay kit (Brucella-Ab C-ELISA, Svanova Biotech AB, Uppsala, Sweden) was used for serological analysis (Centre Veterinary Laboratory, Lilongwe, Malawi). This test distinguishes between Brucella infected animals, Brucella strain 19 vaccinated animals and animals infected with cross-reacting gram-negative bacteria. Samples were tested in singles following the manufacturer's recommendations (Svanova Biotech $\mathrm{AB}$ ) as described elsewhere (Bayemi et al. 2009).

For intradermal tests for bTB, bovine and avian purified protein derivatives (PPD) (supplied by ID-Lelystad, Netherlands, and Veterinary Laboratories Agency, Weybridge, UK, respectively) were used. Intradermal injections of $0.1 \mathrm{~mL}$ of bovine PPD and avian PPD were administered on shaved sites of the mid-neck region. The injection sites were examined $72 \pm 6 \mathrm{~h}$ later and any swelling was measured with a pair of callipers. Interpretation of the results was based on the World Organisation for Animal health (OIE) recommendations (OIE 2009). Briefly, animals with a difference in skin thicknesses after bovine tuberculin and avian tuberculin injections in the subcutaneous immunotherapy test (SCIT) (by subtracting the increase in avian site from the increase in the bovine site) of $>4 \mathrm{~mm}$, $>2 \mathrm{~mm}$ but $<4 \mathrm{~mm}$ and $<2 \mathrm{~mm}$ were considered positive, inconclusive and negative, respectively (OIE 2009).

\section{Statistical Analysis}

The data obtained were entered in Microsoft Excel ${ }^{\circledast}$ (Microsoft, USA) and transferred to Minitab ${ }^{\circledR} 16$ Statistical Software (Minitab, Inc., State College, Pennsylvania, USA). Descriptive statistics were generated and the association between different variables (dairy farmer and farm characteristics) and knowledge or farm practices with regard to zoonoses were assessed by chi-square $\left(\chi^{2}\right)$ test. Odds ratios (OR) and confidence intervals $(\mathrm{CI})$ were calculated to assess potential risk indicators associated with brucellosis seroprevalence in a univariate logistic regression model. Potential risk indicators included in the models were identified based on previously reported risk factors (Shitaye et al. 2007; Swai \& Schoonman 2009, 2010) and on availability of data, under practical conditions in Malawi, such as area, grazing system, origin of cows, breeding practice and age of animals. Unadjusted risk indicators associated with brucellosis in this study in the univariate model $(p \leq 0.25)$ were included in a multivariate logistic model. The age of animals and duration in dairy farming were grouped into two categories each (above respective median value, below respective median value). For all $\chi^{2}$ tests, as well as for logistic univariate and multivariate models, $p$-values $<0.05$ were considered to be significant.

\section{Results}

\section{Knowledge and practices of dairy farmers with regard to zoonoses}

One hundred and eight (108/140) (77.1\%) survey participants had heard or believed that there are diseases that are naturally transmitted between animals and man, $14.0 \%$ (20/140) were not sure, whilst $9.0 \%(12 / 140)$ were certain that they had never heard of such diseases (Table 1$)$. Three-quarters $(105 / 140)$ of the survey participants correctly named at least one zoonotic disease. About two-thirds (95/140) of all the survey participants correctly named one route of zoonotic disease transmission. Bovine tuberculosis was the most commonly named zoonotic disease and milk was the most frequently mentioned potential means of zoonotic disease transmission. Sale of unpasteurised milk was known by most of the farmers to be a potential risk factor for disease transmission.

All survey participants consumed home-produced milk. Almost all survey participants $(96.0 \%)$ practised at least one activity that could lead to milk-borne transmission of bTB or brucellosis, such as no or irregular testing of animals for

TABLE 1: Named zoonotic diseases, possible means of transmission and preventative measures in smallholder dairy farms

\begin{tabular}{|c|c|c|c|}
\hline Variable & Category & Number of survey participants & $\%$ \\
\hline \multirow[t]{6}{*}{ Named zoonotic diseases } & Bovine tuberculosis & 104 & 74.3 \\
\hline & Rabies & 21 & 15.0 \\
\hline & Brucellosis & 4 & 2.9 \\
\hline & Bird flu & 4 & 2.9 \\
\hline & Others $\dagger$ & 8 & 5.7 \\
\hline & Mean number of named zoonoses per farmer ( \pm SEM) & $1.0 \pm 3.6$ & - \\
\hline \multirow[t]{4}{*}{ Mode of transmission } & Contaminated milk & 94 & 67.1 \\
\hline & Contaminated meat & 79 & 56.4 \\
\hline & Aerosol & 33 & 23.6 \\
\hline & Contact with infected animals & 11 & 7.9 \\
\hline \multirow[t]{2}{*}{ Preventive measures } & Medical check-upt & 22 & 15.7 \\
\hline & Veterinary check $\S$ & 26 & 18.6 \\
\hline \multirow[t]{2}{*}{ Milk usage } & Sale to the MBG and public & 71 & 50.7 \\
\hline & Sale to MBG only & 70 & 49.3 \\
\hline \multirow[t]{2}{*}{ Consume only boiled milk at home } & Yes & 92 & 65.7 \\
\hline & No & 48 & 34.3 \\
\hline
\end{tabular}

$\dagger$, Worms, mastitis, name not known.

$\ddagger$ Farmer had gone for tuberculosis test previously.

$\S$, Herd had been checked at least once for zoonotic disease(s).

$n=140$ 
those diseases (26/140), as well as consumption (48/140) or sale $(71 / 140)$ of unpasteurised milk (Table 2$)$. A significantly higher proportion $(p<0.05)$ of farmers from Nkhata Bay district $(51.1 \%)$ consumed unpasteurised milk compared to those in Mzimba district (25.0\%). A higher percentage of women $(57.1 \%)$ compared to men $(37.5 \%)(p<0.02)$ named at least one mode of transmission of zoonotic diseases.

\section{Brucella antibody and tuberculin skin test}

Of the 156 animals tested, $12(7.7 \%)$ had antibodies against Brucella species. In the univariate logistic regression models, a higher age and free or partial grazing were associated with occurrence of antibodies against brucellosis $(p<0.05)$ (Table 3). In the final multivariate logistic regression model, only animals older than or equal to five years were more likely $(\mathrm{OR}=6.97 ; 95.0 \% \mathrm{CI}=1.41-34.36)$ to have experienced $\mathrm{a}$ Brucella infection than those younger than five years. One out of $95(1.1 \%)$ cattle was positive for bTB.

\section{Discussion}

Knowledge of zoonoses amongst dairy farmers was high; more farmers reported bTB $(74.3 \%)$ as a zoonotic disease than brucellosis (15.0\%). A similar observation was made in a study of animal handlers in Cameroon, where $68.0 \%$ knew bTB as zoonotic (Awah Ndukum et al. 2010). The percentage of farmers who named bTB as a zoonotic disease was higher than the $39.6 \%$ and $16.1 \%$ of cattle owners and smallholder dairy farmers in Zambia and Zimbabwe, respectively (Mosalagae et al. 2011; Munyeme et al. 2010). In contrast to both of these other studies, in which the majority $(88.0 \%$ and $74.8 \%$, respectively) of the survey participants were male, most $(60.0 \%)$ of the survey participants in the current study were women. Significantly, in the present study, more women than men named one mode of transmission $(p<0.05)$ and knew of milk-borne diseases $(p=0.05)$, which may explain the overall high-level of awareness observed. The relatively high level of awareness of bTB may also be due to

TABLE 2: Association of some smallholder dairy farmer characteristics, milk-borne disease awareness and milk consumption habits.

\begin{tabular}{|c|c|c|c|c|c|c|c|c|}
\hline \multirow[t]{2}{*}{ Variable } & \multirow[t]{2}{*}{ Category } & \multirow[t]{2}{*}{$n$} & \multicolumn{6}{|c|}{ Number of survey participants } \\
\hline & & & $\begin{array}{l}\text { Aware of at least one } \\
\text { milk-borne disease }\end{array}$ & $\%$ & $\begin{array}{c}\text { Know at least one } \\
\text { mode of transmission }\end{array}$ & $\%$ & $\begin{array}{l}\text { Sometimes drink fresh } \\
\text { or cultured } † \text { milk }\end{array}$ & $\%$ \\
\hline \multirow[t]{2}{*}{ Location } & Nkhata Bay district & 45 & 37 & 82.20 & 35 & 77.80 & 23 & 51.10 \\
\hline & $x^{2}$ ( $p$-value) & - & 1.53 & 0.21 & 0.42 & 0.52 & 8.33 & 0.00 \\
\hline \multirow[t]{2}{*}{ Gender } & Male & 56 & 22 & 39.30 & 21 & 37.50 & 20 & 35.70 \\
\hline & Female & 84 & 47 & 56.00 & 48 & 57.10 & 28 & 33.30 \\
\hline \multirow[t]{3}{*}{ Education } & Below primary education & 100 & 50 & 50.00 & 50 & 50.00 & 34 & 34.00 \\
\hline & Above primary education & 40 & 19 & 47.50 & 19 & 47.50 & 14 & 35.00 \\
\hline & $x 2$ ( $p$-value) & - & 0.07 & 0.79 & 0.07 & 0.79 & 0.08 & 0.77 \\
\hline \multirow{3}{*}{$\begin{array}{l}\text { History of TB in } \\
\text { the family }\end{array}$} & Previous history of TB & 10 & 7 & 70.00 & 7 & 70.00 & 4 & 40.00 \\
\hline & No previous history of TB & 130 & 62 & 47.70 & 62 & 47.70 & 44 & 33.80 \\
\hline & $x^{2}$ ( $p$-value) & - & 1.85 & 0.17 & 1.85 & 0.17 & 0.16 & 0.69 \\
\hline \multirow{2}{*}{$\begin{array}{l}\text { Duration in dairy } \\
\text { farming }\end{array}$} & Below 5 years & 60 & 33 & 55.00 & 33 & 55.00 & 18 & 30.00 \\
\hline & $\chi 2$ ( $p$-value) & - & 1.37 & 0.24 & 1.37 & 0.24 & 0.86 & 0.35 \\
\hline \multirow[t]{3}{*}{ Source of animals } & Personal resources only & 57 & 32 & 56.10 & 31 & 54.40 & 20 & 35.10 \\
\hline & Personal resources and donors & 82 & 37 & 45.10 & 38 & 46.30 & 28 & 34.10 \\
\hline & $\chi 2$ ( $p$-value) & - & 1.63 & 0.20 & 0.87 & 0.35 & 0.01 & 0.91 \\
\hline
\end{tabular}

$\dagger$, non-pasteurised fermented milk.

TABLE 3: Animal-level univariate logistic analysis of risk factors associated with brucellosis seroprevalence.

\begin{tabular}{|c|c|c|c|c|c|c|c|}
\hline Factor & Category & $\begin{array}{l}\text { Numbers } \\
\text { examined }\end{array}$ & $\begin{array}{l}\text { Positive } \\
\text { reactors }\end{array}$ & $\begin{array}{l}\text { Positive } \\
\text { reactors in \% }\end{array}$ & OR & $\mathrm{Cl}(95.0 \%)$ & $p$-value \\
\hline \multirow[t]{2}{*}{ District } & Mzimba & 124 & 10 & 8.1 & 1.33 & $0.27-6.38$ & 0.731 \\
\hline & Nkhata Bay & 32 & 2 & 6.3 & - & - & - \\
\hline \multirow[t]{2}{*}{ Origin of cows } & Imported & 46 & 4 & 8.7 & 1.20 & $0.34-4.21$ & 0.773 \\
\hline & Locally bred & 110 & 8 & 7.3 & - & - & - \\
\hline \multirow[t]{2}{*}{ Grazing system } & Zero & 134 & 8 & 6.0 & 4.07 & $1.09-15.14$ & 0.036 \\
\hline & Free or partial & 22 & 4 & 18.2 & - & - & - \\
\hline \multirow[t]{2}{*}{ Breeding practice } & Al only & 17 & 2 & 11.8 & 2.00 & $0.40-10.12$ & 0.402 \\
\hline & Natural and Al & 139 & 10 & 7.2 & - & - & - \\
\hline \multirow[t]{2}{*}{ Age (years) } & $<5$ & 93 & 2 & 2.1 & 8.58 & $1.81-40.67$ & 0.007 \\
\hline & $\geq 5$ & 63 & 10 & 15.9 & - & - & - \\
\hline \multirow{2}{*}{$\begin{array}{l}\text { History of retained placenta } \\
\text { and/or abortionst }\end{array}$} & Yes & 23 & 3 & 13.0 & 1.86 & $0.46-7.43$ & 0.382 \\
\hline & No & 126 & 9 & 7.1 & - & - & - \\
\hline \multirow[t]{2}{*}{ Lactation number } & $<2$ & 120 & 8 & 6.7 & 1.50 & $0.79-2.84$ & 0.210 \\
\hline & $\geq 2$ & 29 & 4 & 13.8 & - & - & - \\
\hline
\end{tabular}

$\mathrm{OR}$, Odds ratio; $\mathrm{Cl}$, Confidence interval; $\mathrm{Al}$, Artificial insemination

$\dagger$, only female animals were considered

$n=147$ 
tuberculosis in humans, which is closely associated to HIV and AIDS; this is a leading cause of death (estimated at $35.8 \%$ of all deaths) in Malawi (Bowie 2006; Nyirenda 2006).

Unlike tuberculosis, it was found that little is known about brucellosis, which does not reflect the apparent disease burden in animals. Poor knowledge of brucellosis is thought to significantly impede people who are infected with brucellosis from seeking medical services; this is thought to have contributed to under-diagnosis and under-reporting of zoonoses in neighbouring Tanzania (John et al. 2008; Kunda et al. 2007). Given the relatively high number of cattle with antibodies against brucellosis, low level of awareness, low formal education, as well as the unpasteurised milkconsumption habit observed in the present study, this is likely to be the case in northern Malawi (Table 2). Unpasteurised milk is either consumed as fresh milk or as fermented curdled sour milk (chambiko). Higher risk of infection with bTB and brucellosis has been found to be associated with non-heated milk consumption (Fetene et al. 2011; Kochar et al. 2007; Makita et al. 2008). Fermentation of unpasteurised milk to $\mathrm{pH}$ values below $\mathrm{pH} 4.0$ has been shown to not inhibit the growth of Brucella strains (Zuniga Estrada et al. 2005).

This investigation demonstrated that animals are not checked for zoonotic diseases on a regular basis. Few farms $(19.0 \%)$ reported that a veterinarian had tested their animals at least once for a zoonotic disease (mainly tuberculosis) due to cost reasons and lack of knowledge. As previously noted (McDermott \& Arimi 2002), information on zoonotic disease burden in most African countries remains scarce. Although the prevalence recorded in this study (1.1\%) may not be a true reflection of the real situation (because of the small sample size used), reaction to the tuberculin skin test and the presence of antibodies against Brucella infection in dairy cattle demonstrate that these diseases occur in the area. This is also not surprising given that both diseases had been reported previously in Malawian cattle (Bedard et al. 1993). In addition, about $76.0 \%$ of the dairy cattle population in the study area are of exotic breeds (Tebug et al. 2012a), most of which were imported from countries like Zambia and South Africa where brucellosis has also been reported in cattle (Chimana et al. 2010; Hesterberg et al. 2008; Swai \& Schoonman 2010). Brucellosis has a wide clinical spectrum in humans (Kochar et al. 2007) and symptoms might be misdiagnosed for other febrile diseases such as malaria. The results of this study indicate that zoonotic diseases could be transmitted from dairy cattle to humans. Therefore, further investigations, as well as concerted veterinary and medical efforts in the control of zoonotic diseases in Malawi, would be beneficial.

\section{Conclusion}

Evidence of both bTB and brucellosis was present in cattle on smallholder dairy farms in northern Malawi. Most dairy farmers knew bTB to be a zoonotic disease, yet farm practices that constitute a high potential public health risk, such as consumption of unpasteurised milk, were still common. Despite the relatively high number of cattle with antibodies against brucellosis, little was known about this zoonotic disease. Seroprevalence of brucellosis was higher in cows older than five years. Therefore, efforts by both veterinary and medical personnel should focus on effective ways of improving: farmers' knowledge of zoonotic bTB and brucellosis transmission, the development of improved herd disease management plans, and the establishment of food safety systems.

\section{Acknowledgments}

The authors acknowledge the full collaboration of smallholder dairy farmers around Mzuzu, the staff of the Department of Animal health and livestock production (Mzuzu), the staff of Mpoto dairy farmers Association and the Administration of World University Service of Canada, Malawi program, for supporting this study. We are thankful to the management of the Centre Veterinary Laboratory, Lilongwe (Malawi), $\mathrm{Mr}$ H. Banda, Mr P. Dzimbiri and Mr R.B. Nyirongo for their support. We would also like to thank Dr B. Chimera for his helpful suggestions and for facilitating the procurement of reagents used in this study.

\section{Competing interests}

The authors declare that they have no financial or personal relationship(s) that may have inappropriately influenced them in writing this article.

\section{Authors' contributions}

S.F.T. (University of Kiel; International Livestock Research Institute, Kenya) performed most of the experiments, including the planning of the study and the analyses of data, as a PhD-student. M.G.G.C. (Scotland's Rural College) and J.A. (University of Plymouth) made contributions in study conception, data analysis and interpretation. G.R.N. (Central Veterinary Laboratory Lilongwe) and J.P.M. (World University Service of Canada) participated in data acquisition and laboratory analyses. S.W. (University of Kiel) made contributions to statistical analyses and interpretation as well as to drafting of manuscript.

\section{References}

Awah Ndukum, J., Kudi, A.C., Bradley, G., Ane-Anyangwe, I.N., Fon-Tebug, S. \& Tchoumboue, J., 2010, 'Prevalence of bovine tuberculosis in abattoirs of the littoral and Western highland regions of cameroon: A cause for public health concern', Veterinary Medicine International 2010, No. 495015.

Ayele, W.Y., Neill, S.D., Zinsstag, J., Weiss, M.G. \& Pavlik, I., 2004, 'Bovine tuberculosis: An old disease but a new threat to Africa', International Journal of Tuberculosis and Lung Disease 8, 924-37.

Banda, L.J., Gondwe, T.N., Gausi, W., Masangano, C., Fatch, P., Wellard, K., Banda, J.W. \& Kaunda, E.W., 2011, 'Challenges and opportunities of smallholder dairy production systems: A case study of selected districts in Malawi', Livestock Research for Rural Development 23, \#Art. 226, viewed on 02 October 2013, from http://www.lrrd.org/lrrd23/11/band23226.htm

Banda, L.J., Kamwanja, L.A., Chagunda, M.G.G., Ashworth, C.J. \& Roberts, D.J., 2012 'Status of dairy cow management and fertility in smallholder farms in Malawi' Tropical Animal Health and Production 44, 715-727. http://dx.doi.org/10.1007/ s11250-011-9972-4

Bayemi, P.H., Webb, E.C., Nsongka, M.V., Unger, H. \& Njakoi, H., 2009, 'Prevalence of Brucella abortus antibodies in serum of Holstein cattle in Cameroon', Tropical Animal Health and Production 41, 141-144. http://dx.doi.org/10.1007/s11250008-9184-8 
Bedard, B.G., Martin, S.W. \& Chinombo, D., 1993, 'A prevalence study of bovine tuberculosis and brucellosis in Malawi', Preventive Veterinary Medicine 16, 193 205. http://dx.doi.org/10.1016/0167-5877(93)90066-3

Bowie, C., 2006, 'The burden of disease in Malawi', Malawi Medical Journal 18, 103110.

Chimana, H.M., Muma, J.B., Samui, K.L., Hangombe, B.M., Munyeme, M., Matope G. et al., 2010, 'A comparative study of the seroprevalence of brucellosis in commercial and small-scale mixed dairy-beef cattle enterprises of Lusaka province and Chibombo district, Zambia', Tropical Animal Health and Production 42, 1541-1545. http://dx.doi.org/10.1007/s11250-010-9604-4

Fetene, T., Kebede, N. \& Alem, G., 2011, 'Tuberculosis infection in animal and human populations in three districts of Western Gojam, Ethiopia', Zoonoses and Public Health 58, 47-53. http://dx.doi.org/10.1111/j.1863-2378.2009.01265.x

Hesterberg, U.W., Bagnall, R., Perrett, K., Bosch, B., Horner, R. \& Gummow, B., 2008 'Serological prevalence survey of Brucella abortus in cattle of rural communities in the province of KwaZulu-Natal, South Africa', Journal of the South Africa Veterinary Association 79, 15-18. http://dx.doi.org/10.4102/jsava.v79i1.234

John, K., Kazwala, R. \& Mfinanga, G.S., 2008, 'Knowledge of causes, clinical features and diagnosis of common zoonoses among medical practitioners in Tanzania', BMC Infectious Diseases 8, $162 \mathrm{http} / / / \mathrm{dx}$.doi.org/10.1186/1471-2334-8-162

Karimuribo, E., Ngowi, H., Swai, E. \& Kambarage, D., 2007, 'Prevalence of brucellosis in crossbred and indigenous cattle in Tanzania', Livestock Research for Rural Development 19, Art. \#148, viewed on 02 October 2013, from http://www.Irrd. org/Irrd19/10/kari19148.htm

Kazwala, R.R., Daborn, C.J., Kusiluka, L.J.M., Jiwa, S.F.H., Sharp, J.M. \& Kambarage, D.M., 1998, 'Isolation of Mycobacterium species from raw milk of pastoral cattle of the Southern Highlands of Tanzania', Tropical Animal Health and Production 30 233-239. http://dx.doi.org/10.1023/A:1005075112393

Kazwala, R.R., Daborn, C.J., Sharp, J.M., Kambarage, D.M., Jiwa, S.F.H. \& Mbembati, N.A., 2001, 'Isolation of Mycobacterium bovis from human cases of cervical adenitis in Tanzania: A cause for concern?', International Journal of Tuberculosis and Lung Disease 5, 87-91.

Kochar, D.K., Gupta, B.K., Gupta, A., Kalla, A., Nayak, K.C. \& Purohit, S.K., 2007 'Hospital-based case series of 175 cases of serologically confirmed brucellosis in Bikaner', Journal of the Association of Physicians of India 55, 271-275.

Kunda, J., Fitzpatrick, J., Kazwala, R., French, N.P., Shirima, G., MacMillan, A. et al., 2007, 'Health-seeking behaviour of human brucellosis cases in rural Tanzania', BMC Public Health 7, 315. http://dx.doi.org/10.1186/1471-2458-7-315

Makita, K., Fèvre, E.M., Waiswa, C., Kaboyo, W., De Clare Bronsvoort, B.M., Eisler, M.C. et al., 2008, 'Human brucellosis in urban and peri-urban areas of Kampala, Uganda', Annals of the New York Academy of Sciences 1149, 309-311. http:// dx.doi.org/10.1196/annals.1428.015

McDermott, J.J. \& Arimi, S.M., 2002, 'Brucellosis in sub-Saharan Africa: Epidemiology, control and impact', Veterinary Microbiology 90, 111-134. http://dx.doi. org/10.1016/S0378-1135(02)00249-3

Mosalagae, D., Pfukenyi, D.M. \& Matope, G., 2011, 'Milk producers' awareness of milk-borne zoonoses in selected smallholder and commercial dairy farms of Zimbabwe', Tropical Animal Health and Production 43, 733-739. http://dx.doi. org/10.1007/s11250-010-9761-5

Munyeme, M., Muma, J.B., Munang'andu, H.M., Kankya, C., Skjerve, E. \& Tryland, M., 2010, 'Cattle owners' awareness of bovine tuberculosis in high and low
prevalence settings of the wildlife-livestock interface areas in Zambia', BMC Veterinary Research 6, 21. http://dx.doi.org/10.1186/1746-6148-6-21
Mzuzu Agricultural Development Division, 2009, Agricultural Produce Estimates 2009. First round, Mzuzu Agriculture Development Division, Ministry of Agriculture and Food Security, Malawi.

Nyirenda, T., 2006, 'Epidemiology of tuberculosis in Malawi', Malawi Medical Journal 18, 147-159.

OIE, 2009, 'Bovine tuberculosis', Manual of diagnostic tests and vaccines for terrestria animals, World Organisation for Animal Health (OIE), Paris.

OIE, 2012, Global tuberculosis report 2012 - Tuberculosis country profiles, Malawi, World Organisation for Animal Health (OIE), Paris.

Pappas, G., Papadimitriou, P., Akritidis, N., Christou, L. \& Tsianos, E.V., 2006, 'The new global map of human brucellosis', Lancet Infectious Diseases 6, 91-99. http:// dx.doi.org/10.1016/S1473-3099(06)70382-6

Schelling, E., Diguimbaye, C., Daoud, S., Nicolet, J., Boerlin, P., Tanner, M. et al., 2003, 'Brucellosis and Q-fever seroprevalences of nomadic pastoralists and their livestock in Chad', Preventive Veterinary Medicine 61, 279-293. http://dx.doi. org/10.1016/j.prevetmed.2003.08.004

Shitaye, J.E., Tsegaye, W. \& Pavlik, I., 2007, 'Bovine tuberculosis infection in animal and human populations in Ethiopia: A review', Veterinarni Medicina 52, 317-332.

Swai, E.S., Mshanga, D., Sanka, N.P. \& Marandu, N.H., 2005, 'Prevalence of bovine brucellosis in smallholder dairy farming area, Moshi, Tanzania', Bulletin of Animal Health and Production in Africa 53, 97-105. http://dx.doi.org/10.4314/bahpa. v53i2.32695

Swai, E.S. \& Schoonman, L., 2009, 'Human brucellosis: Seroprevalence and risk factors related to high risk occupational groups in Tanga Municipality, Tanzania', Zoonoses and Public Health 56, 183-187. http://dx.doi.org/10.1111/j.18632378.2008.01175.x

Swai, E.S. \& Schoonman, L., 2010, 'The use of rose bengal plate test to assess cattle exposure to Brucella infection in traditional and smallholder dairy production systems of Tanga Region of Tanzania', Veterinary Medicine International 2010, 837950. http://dx.doi.org/10.4061/2010/837950

Swai, E.S. \& Schoonman, L., 2012, 'Differences in prevalence of tuberculosis in indigenous and crossbred cattle under extensive and intensive management systems in Tanga Region of Tanzania', Tropical Animal Health and Production 44 459-465. http://dx.doi.org/10.1007/s11250-011-9919-9

Tebug, S.F., Kasulo, V., Chikagwa-Malunga, S., Wiedemann, S., Roberts, D.J. \& Chagunda, M.G.G., 2012a, 'Smallholder dairy production in Northern Malawi: Production practices and constraints', Tropical Animal Health and Production 44 $55-62$.

Tebug, S.F., Njunga, G.R., Chagunda, M.G.G. \& Wiedemann, S., 2012b, 'Health constraints and farm management factors influencing udder health of dairy cows
in Malawi', Journal of Agricultural Science 4, 136-142. http://dx.doi.org/10.1007/ in Malawi', Journal

Walsh, A.L., Phiri, A.J., Graham, S.M. Molyneux, E.M \& Molyneux, M.E. 2000, 'Bacteremia in febrile Malawian children: Clinical and microbiologic features', Pediatric Infectious Disease Journal 19, 312-318. http://dx.doi. features', Pediatric Infectious Disease Jour
org/10.1097/00006454-200004000-00010

WHO/FAO/OIE, 2004, Report of the WHO/FAO/OIE Joint Consultation on Emerging Zoonotic Diseases, Geneva, Switzerland.

Zuniga Estrada, A., Mota de la Garza, L., Sanchez Mendoza, M., Santos Lopez, E.M., Filardo Kerstupp, S. \& Lopez Merino, A., 2005, 'Survival of Brucella abortus in milk fermented with a yoghurt starter culture', Revista latinoamericana de Microbiología 47, 88-91. 